\title{
DC Bus Stabilization of Li-Ion Battery Based Energy Storage for a Hydrogen/Solar Power Plant for Autonomous Network Applications
}

\author{
Phatiphat Thounthong, Senior Member, IEEE, Suwat Sikkabut, Member, IEEE, Pongsiri Mungporn, \\ Luigi Piegari, Senior Member, IEEE, Babak Nahid-Mobarakeh, Senior Member, IEEE, \\ Serge Pierfederici, and Bernard Davat, Member, IEEE
}

\begin{abstract}
This paper presents an energy management approach for a hybrid energy system comprised of a photovoltaic $(P V)$ array and a polymer electrolyte membrane fuel cell (PEMFC). A single storage device, i.e., a Li-ion battery module, is used in the proposed structure. Linear proportional-integral (PI) and nonlinear flatness-based controllers for dc bus stabilization for power plants are compared. To verify the control approaches, a hardware system is realized with analog circuits for the PV, FC, and battery current control loops (inner controller loops) and with numerical calculation (DSPACE) for the external energy control loops. Experimental results with small-scale devices [namely, a PV array $(800 \mathrm{~W}, 31 \mathrm{~A})$, a PEMFC (1200 W, $46 \mathrm{~A})$, and a Li-ion battery module $(11.6 \mathrm{Ah}, 24 \mathrm{~V})$ ] illustrate the excellent energy management scheme during load cycles, and the nonlinear differential flatness-based control was determined to provide improved dc bus regulation relative to a classical linear PI control method.
\end{abstract}

Index Terms-Flatness control, fuel cells (FCs), Li-ion battery, nonlinear system, photovoltaic (PV).

\section{INTRODUCTION}

$\mathbf{T}$ O FACE the reduced use of fossil fuel resources and the rise of the demand for electricity, renewable power generation approaches have attracted considerable attention. After

Manuscript received July 1, 2014; revised October 29, 2014; accepted December 10, 2014. Date of publication January 8, 2015; date of current version July 15, 2015. Paper 2014-ESC-0240.R1, presented at 2014 IEEE Industry Applications Society Annual Meeting, Vancouver, BC, Canada, October 5-9, and approved for publication in the IEEE TRANSACTIONS ON INDUSTRY APPLICATIONs by the Energy Systems Committee of the IEEE Industry Applications Society. This work was supported in part by a research program in cooperation with the Thai-French Innovation Institute, King Mongkut's University of Technology North Bangkok (Thailand), with the Université de Lorraine (France) under Contract KMUTNB-GOV-58-01.

P. Thounthong is with the Renewable Energy Research Centre, Department of Teacher Training in Electrical Engineering, Faculty of Technical Education, King Mongkut's University of Technology North Bangkok, Bangkok 10800, Thailand (e-mail: phtt@kmutnb.ac.th).

S. Sikkabut and P. Mungporn are with the Renewable Energy Research Centre, Thai-French Innovation Institute, King Mongkut's University of Technology North Bangkok, Bangkok 10800, Thailand (e-mail: suwatsi@ kmutnb.ac.th; pongsirim@kmutnb.ac.th).

L. Piegari is with the Dipartimento di Elettronica, Informazione e Bioingegneria (DEIB), Politecnico di Milano, 20133 Milan, Italy (e-mail: luigi.piegari@ polimi.it).

B. Nahid-Mobarakeh, S. Pierfederici, and B. Davat are with the Groupe de Recherche en Electrotechnique et Electronique de Nancy, Université de Lorraine, 54000 Nancy, France (e-mail: babak.Nahidmobarakeh@univ-lorraine.fr; Serge.Pierfederici@univ-lorraine.fr; Bernard.Davat@ensem.inpl-nancy.fr).

Color versions of one or more of the figures in this paper are available online at http://ieeexplore.ieee.org.

Digital Object Identifier 10.1109/TIA.2015.2388853 a long period of development, photovoltaic (PV) generators appear to be the most promising candidates. According to the motivation policies in many countries to help PV development and considering the reduction of the costs, expansion of PV systems is expected to continue in the near future [1].

However, the power output of PV generators is not reliable. For example, the power output of PV generators is not available during cloudy conditions or during the night. Other renewable sources, such as fuel cells (FCs), may be more reliable than PV generators but have economic issues [2]. As a result, two or more renewable-energy sources are required to guarantee a reliable and cost-effective power solution. Such a combination of different types of energy sources into a system is known as a hybrid power system [3], [4].

For autonomous network applications, an energy storage device is compulsory. Modern Li-ion batteries are increasingly being used in high-power applications [5], [6]. In this paper, a Li-ion battery module is considered as an energy storage in a proposed solar/hydrogen power plant.

Control, stability, and optimization of distributed generation systems remain an essential area of research. This paper presents a performance comparison between a classical linear control and a differential flatness-based control for dc grid stabilization of a hydrogen/solar hybrid power source with a Li-ion battery energy storage device. The results of this study will provide an important contribution to the field of power electronics applications. In Section II, the PV, FC, and battery converter structures of multisegment power converters are presented in detail, including a mathematical model of the power plant that includes such power converters. The control laws based on the linear proportional-integral (PI) control and the differential flatness property in Section III will be explained in detail. The experimental results revealed the system performances of the linear and nonlinear control laws. The summary and conclusion are presented in Section IV.

\section{HYBRID POWER PLANT}

\section{A. System Configuration Studied}

The proposed power converters structure of a renewable hybrid power plant is portrayed in Fig. 1. The battery converter has four-phase parallel bidirectional converters (two-quadrant converters), and the PV and FC converters have four-phase parallel boost converters. 


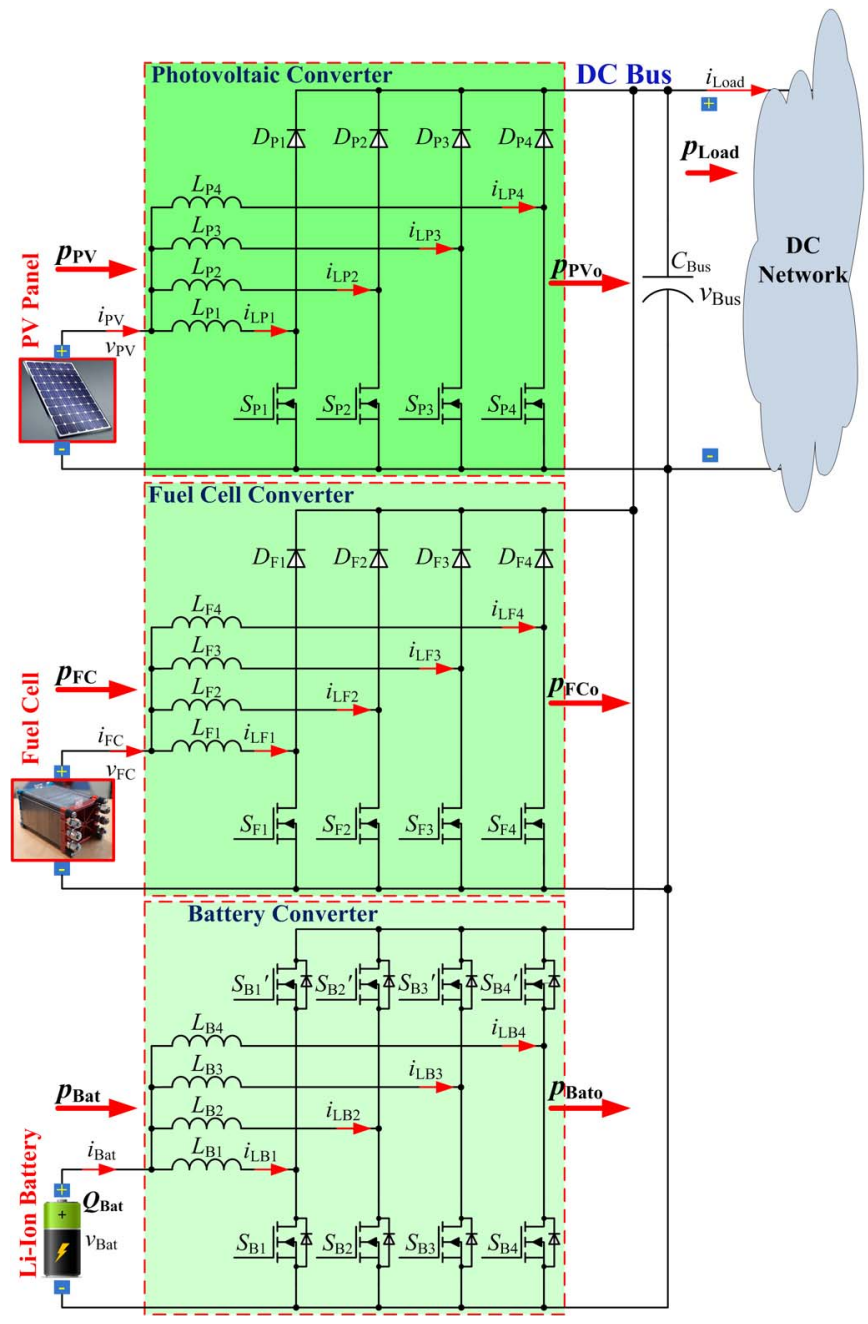

Fig. 1. Proposed power converter structure of a power plant supplied by a PV, an $\mathrm{FC}$, and a Li-ion battery.

For optimization of the power converters, these converters are connected in parallel using an interleaved switching technique. An interleaved system can realize savings in filtration and energy storage requirements, resulting in greatly improved power conversion densities without sacrificing efficiency [7].

For reasons of safety and dynamics, the PV, FC, and battery converters are generally regulated principally by inner current regulation loops based on the classical cascade control structure [8], [9]. The dynamics of inner control loops are much faster than those of outer control loops, which are described shortly. Consequently, the PV current $i_{\mathrm{PV}}$, the $\mathrm{FC}$ current $i_{\mathrm{FC}}$, and the battery current $i_{\text {Bat }}$ are estimated to track completely their setpoints of $i_{\mathrm{PVREF}}, i_{\mathrm{FCREF}}$, and $i_{\mathrm{BatREF}}$, respectively.

\section{B. Model of the Power Plant}

We estimate that the PV, FC, and battery currents track their set-point values perfectly. Thus, the inner control loops of the PV, FC, and battery powers can be estimated as a unity gain. The PV power set-point $p_{\mathrm{PVREF}}$, the FC power set-point $p_{\mathrm{FCREF}}$, and the batter power set-point $p_{\mathrm{BatREF}}$ are

$$
\begin{aligned}
& p_{\mathrm{PVREF}}=p_{\mathrm{PV}}=v_{\mathrm{PV}} \cdot i_{\mathrm{PV}} \\
& p_{\mathrm{FCREF}}=p_{\mathrm{FC}}=v_{\mathrm{FC}} \cdot i_{\mathrm{FC}} \\
& p_{\mathrm{BatREF}}=p_{\mathrm{Bat}}=v_{\mathrm{Bat}} \cdot i_{\mathrm{Bat}} .
\end{aligned}
$$

Hence, the dc bus capacitive energy $y_{\text {Bus }}$ can be written as

$$
y_{\mathrm{Bus}}=\frac{1}{2} C_{\mathrm{Bus}} v_{\mathrm{Bus}}^{2} \text {. }
$$

We suppose that there are only static losses in these converters, in which $r_{\mathrm{PV}}, r_{\mathrm{FC}}$, and $r_{\mathrm{Bat}}$ represent the only static losses in the PV, the FC, and the battery converters, respectively. As shown in Fig. 1, the derivative of the dc bus capacitive energy $y_{\mathrm{Bus}}$ is given versus $p_{\mathrm{PVo}}, p_{\mathrm{FCo}}, p_{\mathrm{Bato}}$, and $p_{\text {Load }}$ by the following differential equation:

$$
\dot{y}_{\text {Bus }}=p_{\text {PVo }}+p_{\text {FCo }}+p_{\text {Bato }}-p_{\text {Load }}
$$

where

$$
\begin{aligned}
& p_{\mathrm{PVo}}=p_{\mathrm{PV}}-r_{\mathrm{PV}}\left(\frac{p_{\mathrm{PV}}}{v_{\mathrm{PV}}}\right)^{2} \\
& p_{\mathrm{FCo}}=p_{\mathrm{FC}}-r_{\mathrm{FC}}\left(\frac{p_{\mathrm{FC}}}{v_{\mathrm{FC}}}\right)^{2} \\
& p_{\text {Bato }}=p_{\mathrm{Bat}}-r_{\mathrm{Bat}}\left(\frac{p_{\mathrm{Bat}}}{v_{\mathrm{Bat}}}\right)^{2} \\
& p_{\text {Load }}=v_{\mathrm{Bus}} \cdot i_{\text {Load }}=\sqrt{\frac{2 y_{\mathrm{Bus}}}{C_{\mathrm{Bus}}}} \cdot i_{\mathrm{Load}} .
\end{aligned}
$$

\section{ENERgy MANAGEMENT}

In the studied system shown in Fig. 1, there are two voltage variables, or two energy variables, to be controlled.

1) First, the dc bus energy $y_{\text {Bus }}$ is the most significant variable.

2) Second, the battery energy capacity $Q_{\text {Bat }}$ is the next most important.

Thus, based on the recent works [10], exploitation of an energy storage device, which represents the fastest energy source in the studied system, is proposed to deliver the energy for the dc bus. Thus, the PV and FC provide energy for the battery cells to keep them charged, so that the battery is operated as the highest dynamic power source to supply the microcycles and the fast dynamic power supply. The FC generator functions as the lowest dynamic power source. The FC current or power slope must be limited to avoid the fuel starvation phenomenon [10]. The FC limited power slope was experimentally determined to be the highest slope of an operating FC system, where no fuel starvation occurs to improve its lifetime [10].

\section{A. DC Bus Stabilization}

The performance comparison between a classical linear control and a nonlinear control based on a differential flatness approach for dc link regulation of a hybrid power plant is presented as follows.

1) Linear Control: First, the classic linear control approach presented in [10] was studied on the power plant. A dc bus capacitive energy set-point was defined by $y_{\mathrm{BusREF}}\left(=y_{\mathrm{REF}}\right)$. A PI control algorithm is given by

$p_{\text {BatREF }}=K_{P}\left(y_{\text {BusREF }}-y_{\text {Bus }}\right)+K_{I} \int_{0}^{t}\left(y_{\text {BusREF }}-y_{\text {Bus }}\right) d \tau$

where $K_{I}$ and $K_{P}$ are the controller parameters. 


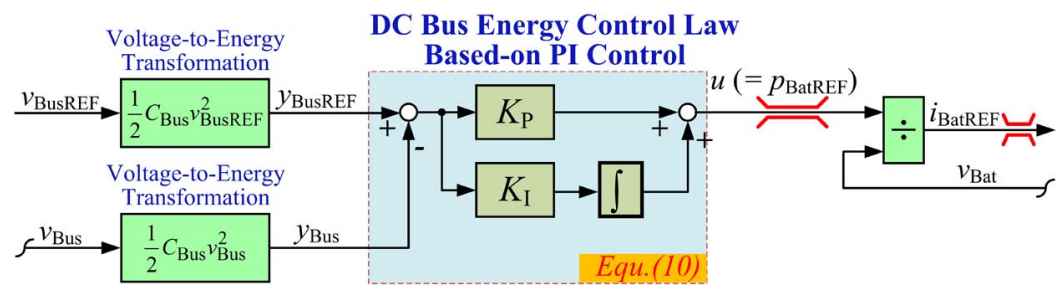

Fig. 2. DC bus energy stabilization based on linear PI control.

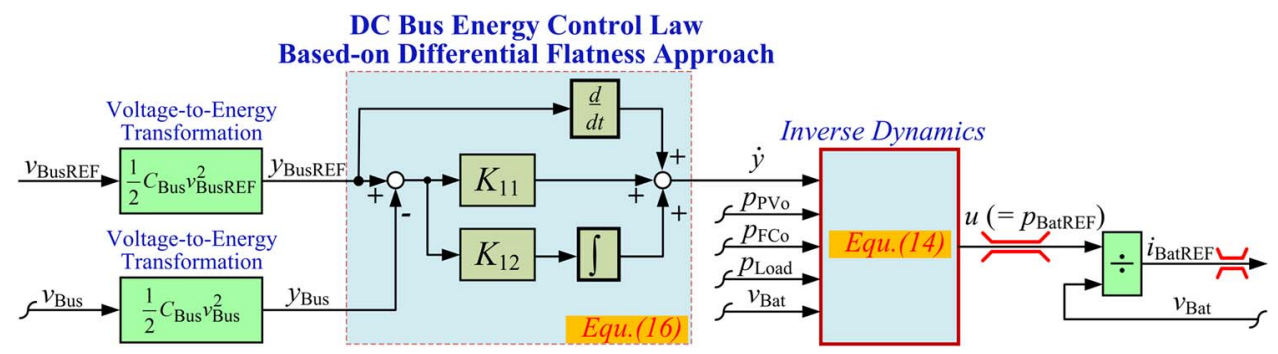

Fig. 3. DC bus energy stabilization based on differential flatness approach.

Because the inner battery current loop is much faster than the external dc bus energy control [such that it can be estimated as a pure unity gain; refer to (5)], the open-loop transfer function associated with the dc bus energy stabilization can be expressed as

$$
\frac{y_{\text {Bus }}(s)}{y_{\text {BusREF }}(s)}=\overbrace{\left(K_{P}+\frac{K_{I}}{s}\right)}^{\text {PI-Controller }} \cdot \overbrace{\frac{1}{s}}^{E_{\text {Bus }} / p_{\text {Bat }}} \cdot \overbrace{\frac{1}{T_{p} s+1}}^{p_{\text {Bat }} / p_{\text {BatREF }}}
$$

where $T_{p}$ is the time constant of an equivalent first-order function of the inner battery power control loop. The PI controller generates a battery power reference $p_{\text {BatREF }}$, as presented in Fig. 2. This signal is divided by the measured battery voltage $v_{\text {Bat }}$, which yields battery current reference $i_{\text {BatREF }}$ for the inner control loop.

2) Nonlinear Differential Flatness Control [11]-[13]: Second, the flat output $y$, control variable $u$, and state variable $x$ are defined as follows:

$$
y=y_{\text {Bus }} \quad u=p_{\text {Bat }} \quad x=v_{\text {Bus }} .
$$

From (4), the state variables $\boldsymbol{x}$ can be expressed as

$$
x=\sqrt{\frac{2 y}{C_{\mathrm{Bus}}}}=\varphi(y) .
$$

From (5), the control variables $\boldsymbol{u}$ can be estimated from the flat output $\boldsymbol{y}$ and its time derivatives

$$
\begin{aligned}
u & =2 p_{\text {BatMax }}\left[1-\sqrt{1-\left(\frac{\dot{y}+\sqrt{\frac{2 y}{C_{\text {Bus }}}} \cdot i_{\text {Load }}-p_{\text {PVo }}-p_{\mathrm{FCo}}}{p_{\text {BatMax }}}\right)}\right] \\
& =\psi(y, \dot{y})=p_{\text {BatREF }}
\end{aligned}
$$

where

$$
p_{\text {BatMax }}=\frac{v_{\text {Bat }}^{2}}{4 r_{\text {Bat }}} .
$$

In this case, $p_{\text {BatMax }}$ is the limited maximum power of the battery source.
Thus, it is clear that $x=\varphi(y)$ and $u=\psi(y, \dot{y})$; consequently, the proposed reduced order system can be estimated as a differential flatness system [12]-[15].

A feedback control law that performs exponential asymptotic tracking is defined by [16]-[18]

$$
\left(\dot{y}-\dot{y}_{\mathrm{REF}}\right)+K_{11}\left(y-y_{\mathrm{REF}}\right)+K_{12} \int\left(y-y_{\mathrm{REF}}\right) d \tau=0
$$

where the controller parameters $\left(K_{11}, K_{12}\right)$ are chosen as the roots of the closed-loop characteristic polynomial.

The studied nonlinear control law of the dc bus regulation is portrayed in Fig. 3; it is similar to the classical linear control law. The key difference between the classical linear control and the differential flatness control is that the inverse dynamic term, known as the flatness property, is present in the control system.

3) Performance Evaluation Between Linear Control and Nonlinear Control Laws for DC Bus Regulation: To validate the control methods, the test bench was implemented in the laboratory (refer to Appendix A). To give a practical comparison between the control methods, the parameters of the linear controller $K_{P}$ and $K_{I}$ were tuned to obtain the best possible performance. The symmetrical optimum (SO) [19], [20] is studied. The method has well-established tuning rules and has a good disturbance rejection. The resulting control system provides an overshoot of approximately $43 \%$, a settling time of approximately $16.3 \cdot T_{p}$, and a phase margin (PM) of 30-60 . In this case, $K_{P}=150 \mathrm{WJ}^{-1}$, and $K_{I}=5500(\mathrm{Js})^{-1}$, so that the desired PM was $30^{\circ}$. If $K_{P}=80 \mathrm{WJ}^{-1}$ and $K_{I}=$ $1500 \mathrm{~W}(\mathrm{Js})^{-1}$, then the desired PM was $55^{\circ}$. For the differential flatness approach, the nonlinear controller gains used were $K_{11}=320 \mathrm{rad} \cdot \mathrm{s}^{-1}$ and $K_{12}=6400 \mathrm{rad}^{2} \cdot \mathrm{s}^{-2}$, so that the system damping ratio $\zeta$ was equal to 2 and the natural frequency $\omega_{n}$ was equal to $80 \mathrm{rad} \cdot \mathrm{s}^{-1}$.

Fig. 4 shows the experimental results obtained for both controllers during the large load step. The oscilloscope waveforms show the dc bus voltage dynamics to the load power demanded 

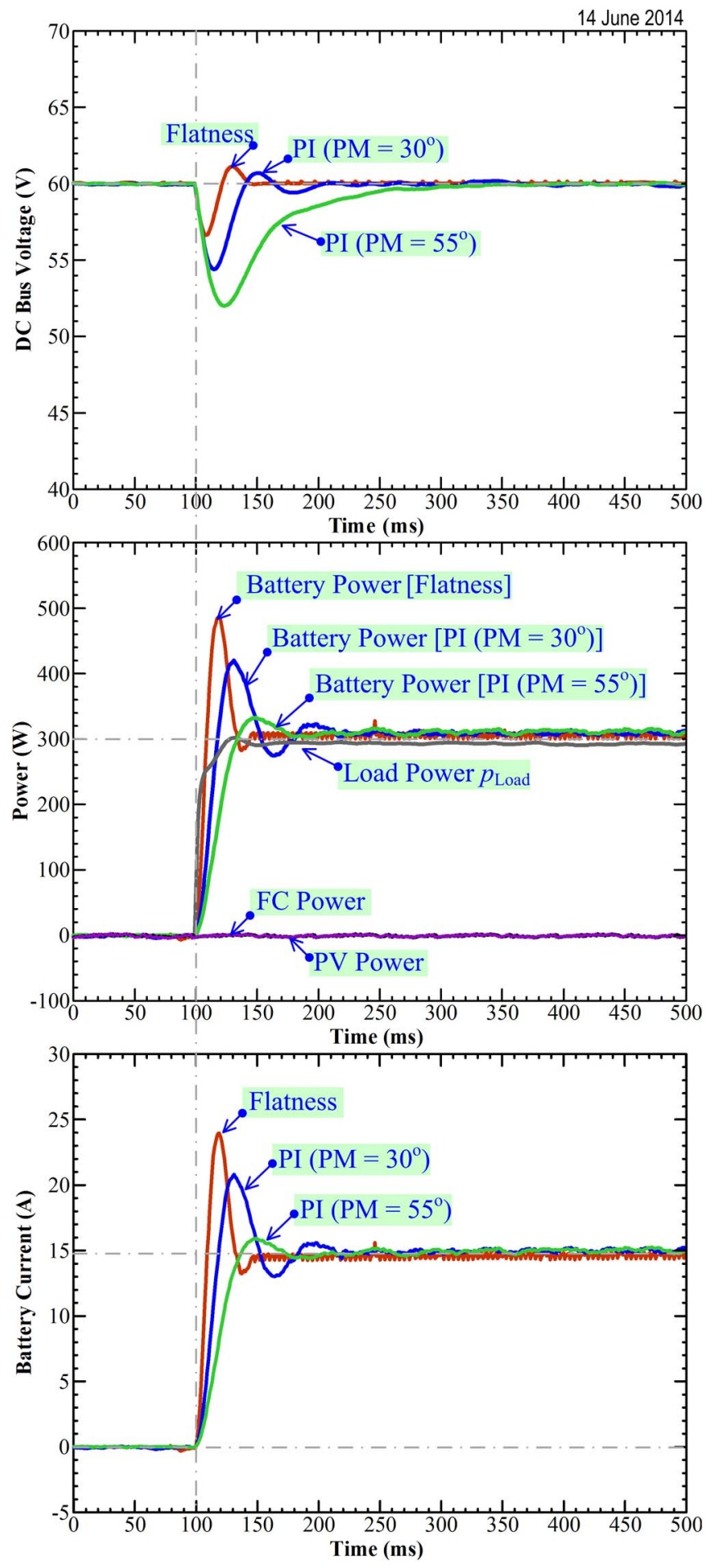

Fig. 4. Comparison of the linear PI control law with a flatness-based control law during a load step.

(disturbance) from 0 to $300 \mathrm{~W}$, whereas the dc bus was loaded with an electronic load. It shows the following:

1) the dc bus voltage at different controllers;

2) the load power;

3) the battery power at different controllers.

The initial state was the no-load power state, the storage device was fully charged, and the dc bus voltage reference was set to $60 \mathrm{~V}\left(=v_{\mathrm{Bus}}\right)$; as a result, the $\mathrm{FC}, \mathrm{PV}$, and battery powers were zero. However, to scrutinize the dc bus voltage regulation by the battery bank, the FC and PV powers are set manually to zero. At $t=100 \mathrm{~ms}$, the load is stepped to its final level of $300 \mathrm{~W}$. One may observe that, although the dynamic response of the linear control algorithm could be improved relative to that shown in the figures, this enhancement comes at the expense of a reduced stability boundary (increasing overshoot and oscillation). Thus, the flatness-based control exhibits good stability and optimum response of the dc bus stabilization.

In conclusion, in the proposed approach, the knowledge of the dynamic behavior of the system enables generation of the battery power reference ( $\left.p_{\text {BatREF }}\right)$ given by (14). Thus, if the system is perfectly known, an open-loop control can be generated by (14). If the reference trajectory is given by $\left[u=\psi\left(y_{\mathrm{REF}}, \dot{y}_{\mathrm{REF}}\right)\right]$, then the control law introduced in (16) has the objective to compensate modeling errors and ensure good tracking performances $\left[u=\psi\left(y_{\mathrm{REF}}, \dot{y}\right)\right]$. Therefore, in comparison with a PI controller, the dynamic behavior achieved via the flatness approach is improved. Indeed, for the PI controller, after disturbances, the control must find the new value of the power reference at this new operating point without information given by the relation (14). Thus, with the flatnessbased approach, the convergence via the new operating point is faster.

\section{B. Charging Li-Ion Battery}

To charge the battery, the steady-state power balance (without losses) may be written as

$$
p_{\text {Bat }}+p_{\text {Load }}=\overbrace{p_{\text {PV }}+p_{\text {FC }}}^{p_{\text {Total }}} .
$$

The proposed special control structure for charging the battery is presented in Fig. 5. The familiar battery SOC estimation is defined as

$$
\operatorname{SOC}(t)=\operatorname{SOC}_{o}+\frac{1}{Q_{\mathrm{Bat}}} \int_{t_{o}}^{t} i_{\mathrm{Bat}}(\tau) d \tau
$$

where $\mathrm{SOC}_{o}$ is the known battery SOC (in percent) at the time $t_{o}$ and $Q_{\mathrm{Bat}}$ is the rated capacity (in ampere hour). The capacity versus current characteristics of the SAFT Li-ion battery (model: MP 174865) are illustrated in Fig. 6, which is also used in the test bench.

The simple method to charge the battery is via the constant current approach (maximum charging current $I_{\mathrm{BatCH}}$ is set to approximately $Q_{\text {Bat }} / 2-Q_{\text {Bat }} / 5$; for a Li-ion battery, it can be set at $I_{\mathrm{BatCH}}=Q_{\mathrm{Bat}}$ ) when the SOC is far from the state of charge reference $\mathrm{SOC}_{\mathrm{REF}}$, the use of a reduced current when the $\mathrm{SOC}$ is near $\mathrm{SOC}_{\mathrm{REF}}$, and zero when the $\mathrm{SOC}$ is equal to $\mathrm{SOC}_{\mathrm{REF}}$.

According to this state of charge algorithm, a proportional (P) controller is sufficient to generate a battery power demand $p_{\text {BatDEM }}$. The P-controller gain $\left(K_{2}\right)$ can be sized as

$$
K_{2}=\frac{P_{\text {BatMax }}}{\Delta \mathrm{SOC}}
$$




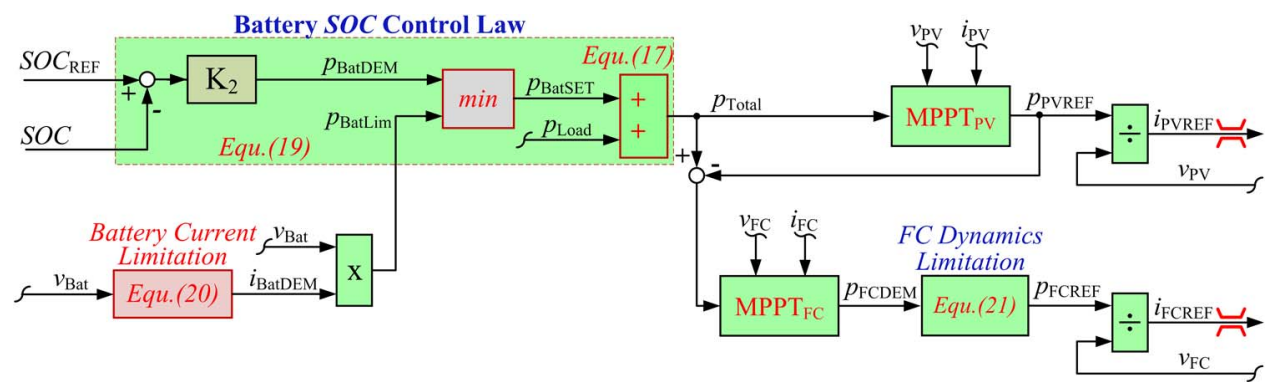

Fig. 5. Battery charging algorithm.

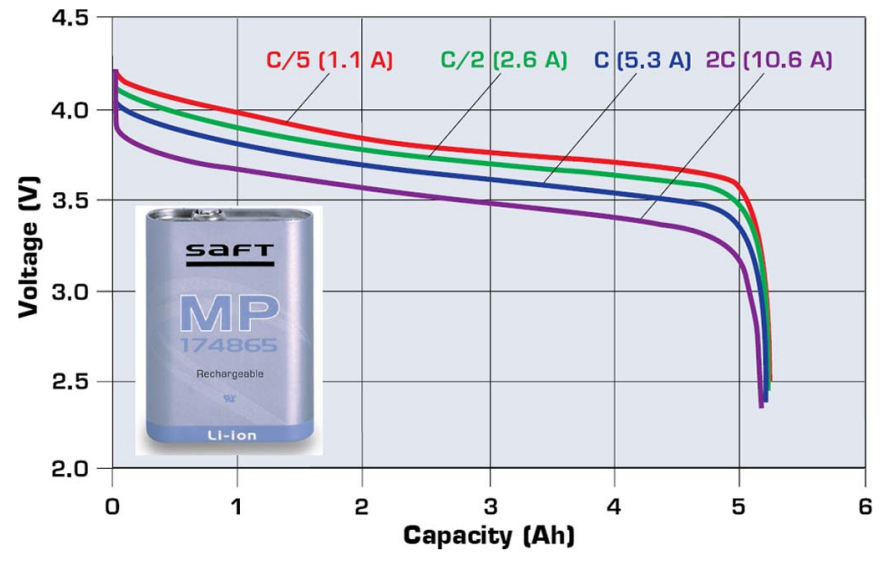

Fig. 6. Typical Li-ion battery cell: capacity versus current at $+20^{\circ} \mathrm{C}$ based on SAFT Technology (model: MP 174865).

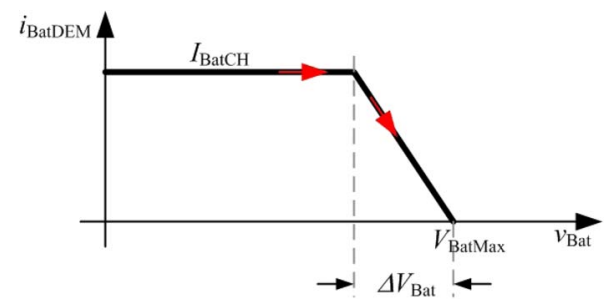

Fig. 7. Battery charging limitation function.

where $\triangle \mathrm{SOC}$ is the defined band of the battery SOC and $P_{\text {BatMax }}$ is the defined maximum battery power charging. Referring to Fig. $7, p_{\text {BatSET }}=\min \left[p_{\text {BatREF }}, p_{\text {BatLim }}\right]$, in which $p_{\text {BatLim }}$ is generated by $v_{\text {Bat }} \times i_{\text {BatDEM }}$. Thus, $i_{\text {BatDEM }}$ is the charging limitation function (Fig. 7) generated by

$$
i_{\mathrm{BatDEM}}=I_{\mathrm{BatCH}} \cdot \min \left(1, \frac{V_{\mathrm{BatMax}}-v_{\mathrm{Bat}}}{\Delta V_{\mathrm{Bat}}}\right)
$$

where $V_{\text {BatMax }}$ is the defined maximum battery voltage and $\Delta V_{\text {Bus }}$ is the defined voltage band.

Therefore, the system generates a total power reference $p_{\text {Total }}$. First, $p_{\text {Total }}$ is considered as the PV power. The power must be limited in level, within an interval of the maximum of $p_{\mathrm{PVMax}}$ (maximum power point tracking $\mathrm{MPPT}_{\mathrm{PV}}$ [21][24]) and the minimum of $p_{\text {PVMin }}$ (set to $0 \mathrm{~W}$ ). Second, the difference between the total power reference $p_{\text {Total }}$ and the PV power reference $p_{\text {PVREF }}$ is the FC power. The power must be limited in level, within an interval of the maximum $p_{\mathrm{FCMax}}$ and the minimum $p_{\mathrm{FCMin}}$ (set to $0 \mathrm{~W}$ ), and limited in dynamics with respect to the constraints that are associated with the FC [25][29]. Then, to limit the transient FC power, a second-order filter is used, such that the power demand $p_{\mathrm{FCDEM}}$ from $\mathrm{MPPT}_{\mathrm{FC}}$ is always limited by

$$
p_{\mathrm{FCREF}}(t)=p_{\mathrm{FCDEM}}(t) \cdot\left(1-e^{-\frac{t}{\tau_{1}}}-\frac{t}{\tau_{1}} e^{-\frac{t}{\tau_{1}}}\right)
$$

where $\tau_{1}$ is the control parameter.

\section{System Performance of a Hybrid Power Source Control Based on the Flatness Control Approach}

In this section, the dc bus energy regulation based on the differential flatness estimation is performed. Fig. 8 presents the waveforms that are obtained during the long load cycles. The dc bus voltage reference and the battery SOC reference are set at $60 \mathrm{~V}$ and $100 \%$, respectively. The maximum FC power $P_{\text {FCMax }}$ is set at $500 \mathrm{~W}$ for a small-scale test. The experimental tests were performed by connecting a dc bus voltage of $60 \mathrm{~V}$ loaded by an electronic load. The parameters associated with the system regulation loops are summarized in Table I.

The load will be varied to emulate the real environment: light load, overload, and transient transitions. The graph shows the dc bus voltage, the PV voltage, the FC voltage, the load power, the battery power, the PV power, the FC power, the battery current, the battery voltage, and the battery SOC.

It should be noted that the results shown in Fig. 8 are obtained at a sampling rate of $25 \mathrm{~S} / \mathrm{s} \quad(=10000$ points stored or a sampling time of $40 \mathrm{~ms}$ ). This will limit the observation of the dc bus voltage perturbations. However, the dc bus voltage perturbations were clearly visible for the first case study shown in Fig. 4 since the sampling rate was $10 \mathrm{kS} / \mathrm{s}(=5000$ points stored or a sampling time of $0.1 \mathrm{~ms}$ ).

In the initial state, the small load power is equal to $100 \mathrm{~W}$, and the battery is full of charge, i.e., $\mathrm{SOC}=\mathrm{SOC}_{\mathrm{REF}}=100 \%$; as a result, the PV source supplies power for the load of $100 \mathrm{~W}$ (because, if $p_{\text {PVMax }}>p_{\text {PVDEM }}$, then $p_{\text {PVREF }}=p_{\text {PVDEM }}$ ), and the FC and battery powers are zero. 


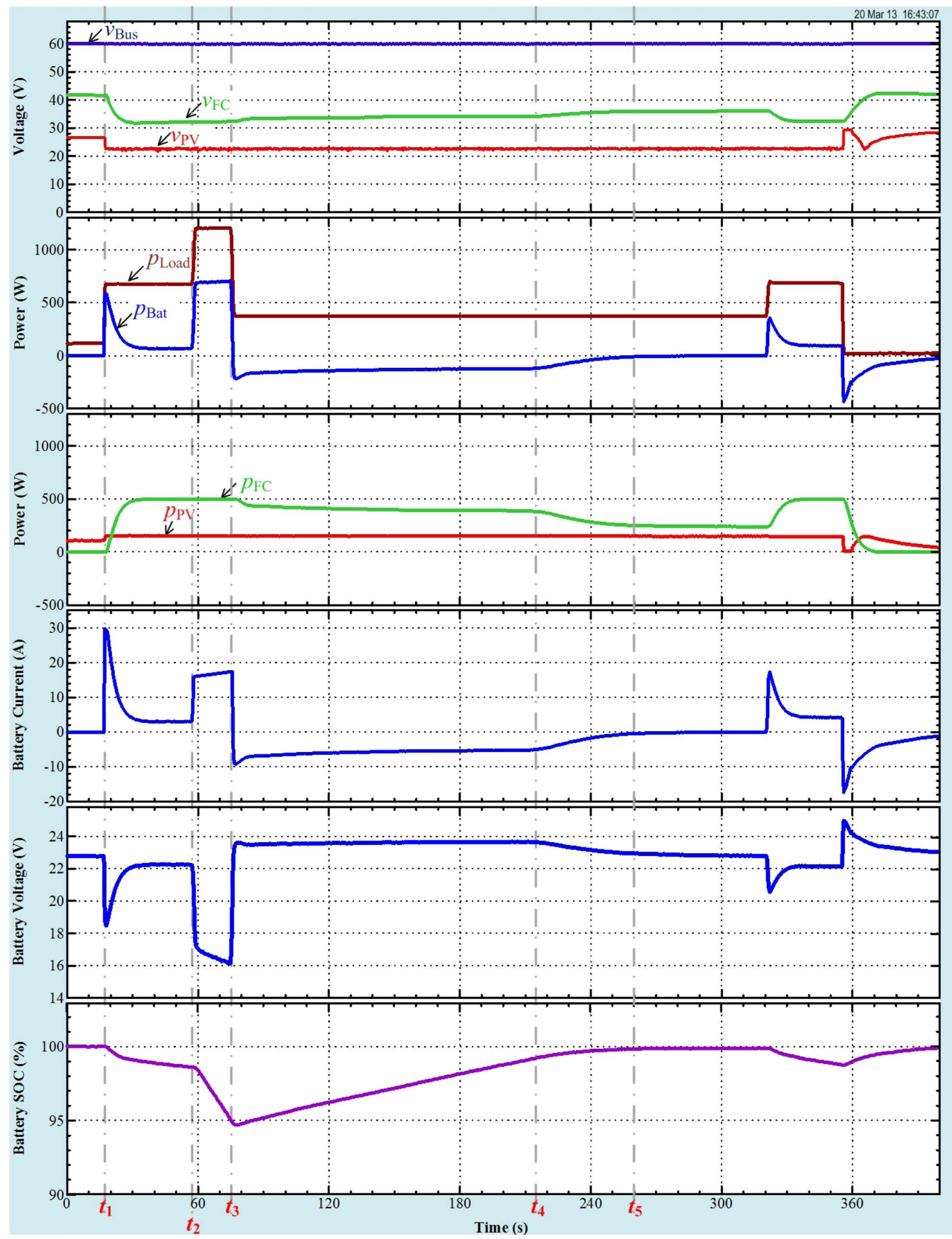

Fig. 8. Experimental results: power plant response during load cycles.

At $t_{1}(=18 \mathrm{~s})$, the load power steps from $100 \mathrm{~W}$ to the constant power of $700 \mathrm{~W}$. The following observations are made.
1) The battery supplies most of the transient step load.

2) At the same time, the PV power increases to a maximum power point (MPP) of approximately $150 \mathrm{~W}$, which is 
TABLE I

SYSTEM PARAMETERS

\begin{tabular}{lll}
\hline$v_{\text {BusREF }}$ & 60 & $\mathrm{~V}$ \\
$S O C_{\mathrm{REF}}$ & $100 \%$ & \\
$K_{11}$ & 320 & $\mathrm{rad} \cdot \mathrm{s}^{-1}$ \\
$K_{12}$ & 6,400 & $\mathrm{rad}^{2} \cdot \mathrm{s}^{-2}$ \\
$K_{2}$ & 200 & \\
$\tau_{1}$ & 5 & $\mathrm{~s}$ \\
$\Delta V_{\mathrm{Bat}}$ & 1 & $\mathrm{~V}$ \\
$V_{\mathrm{BatMax}}$ & 25 & $\mathrm{~V}$ \\
$I_{\mathrm{BatCH}}$ & 10 & $\mathrm{~A}$ \\
$P_{\mathrm{FCMax}}$ & 500 & $\mathrm{~W}$ \\
$C_{\mathrm{Bus}}$ & 8,000 & $\mu \mathrm{F}$ \\
$r_{\mathrm{FC}}$ & 0.13 & $\Omega$ \\
$r_{\mathrm{PV}}$ & 0.14 & $\Omega$ \\
$r_{\mathrm{Bat}}$ & 0.18 & $\Omega$ \\
\hline
\end{tabular}

limited by the maximum power point tracker (MPPT) because, if $p_{\text {PVMax }}<p_{\text {PVDEM }}$, then $p_{\text {PVREF }}=p_{\text {PVMax }}$. Due to a cloudy sky during the test bench validation, the MPP is only $150 \mathrm{~W}$ instead of its rated PV power of $800 \mathrm{~W}$.

3) Simultaneously, the FC power increases with limited dynamics to the limited maximum power of $500 \mathrm{~W}$.

4) The input from the battery, which supplies most of the transient power that is required during the stepped load, slowly decreases, and the unit remains in a discharge state after the load step because the steady-state load power $(700 \mathrm{~W})$ is greater than the total power supplied by the $\mathrm{PV}$ and FC.

At $t_{2}(=58 \mathrm{~s})$, the large load power steps from $700 \mathrm{~W}$ to the constant power of $1200 \mathrm{~W}$. The following clarifications are made.

1) The PV and FC powers are at the maximum power levels.

2) The battery is deeply discharged to deliver power to the load power demand.

Subsequently, at $t_{3}(=76 \mathrm{~s})$, the load power steps from 1200 to $350 \mathrm{~W}$, and $\mathrm{SOC}_{\mathrm{REF}}(=100 \%)>\mathrm{SOC}(=95 \%)$. As a result, the battery changes its state from discharging to charging, demonstrating the three phases.

1) First, the PV still supplies its limited maximum power. The FC power is intelligently reduced for driving the load and for charging the battery.

2) Second, at $t_{4}(=215 \mathrm{~s}, \mathrm{SOC}=99 \%)$, the battery is nearly charged at $100 \%$, which subsequently reduces the charging power. As a result, the $\mathrm{FC}$ power is reduced.

3) Third, at $t_{5}(=260 \mathrm{~s}, \mathrm{SOC}=100 \%)$, the battery is fully charged. As a result, only the PV and FC generators supply power for the load of $350 \mathrm{~W}$. The battery power is zero.

One can observe that the power plant is always energy balanced $\left(p_{\mathrm{Load}}=p_{\mathrm{PV}}+p_{\mathrm{FC}}+p_{\mathrm{Bat}}\right)$ when using the proposed original control algorithm.

\section{CONCLUSION}

The primary objectives of this paper were to study the dc bus stabilization based on either linear or nonlinear control

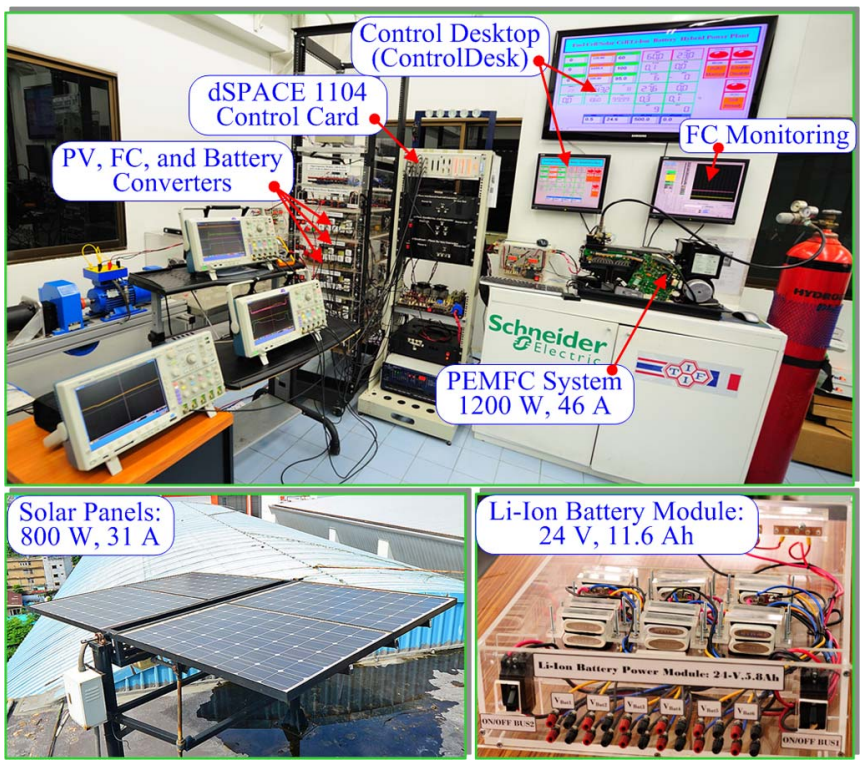

Fig. 9. Photograph of the experimental setup in the laboratory (Renewable Energy Research Centre, KMUTNB).

approach for the Li-ion battery storage device coupled to a renewable-energy power plant and to study how to charge the Li-ion battery using the special control algorithm. The nonlinear differential flatness approach of a hydrogen/solar power plant of the load rejection transient offers superior $\mathrm{dc}$ link regulation. Nevertheless, the classical PI controller, being a current standard industrial controller solution, will continue to be compared to various new control algorithms that will emerge in the future.

For the classical linear control, there is no load current measurement. Conversely, the nonlinear flatness-based control requires a load current measurement to estimate the load power to obtain the differential flatness property. For future works, a load observer will be used to avoid the measurement of the load current; in addition, a loss observer will be used for online realtime calculation.

\section{APPENDIX \\ TEST BENCH DESCRIPTION of THE POWER PLANT}

The prototype test bench of the studied power plant was implemented in the laboratory, as illustrated in Fig. 9. The prototype $\mathrm{PV}$ converter of $2 \mathrm{~kW}$, the $\mathrm{FC}$ converter of $2 \mathrm{~kW}$, and the battery converter of $4 \mathrm{~kW}$, as demonstrated in Fig. 10 were realized in the RERC laboratory. The details of the real power sources and Li-ion battery module are presented in Table II. Note that the PV array is installed on the roof of the laboratory building (Fig. 9), so that the solar energy production is directly from the sun.

The PV, FC, and battery current regulation loops were realized by analog circuits as inner current control loops. The control algorithms (external control loops), which generate the current references, were implemented in the real-time card 

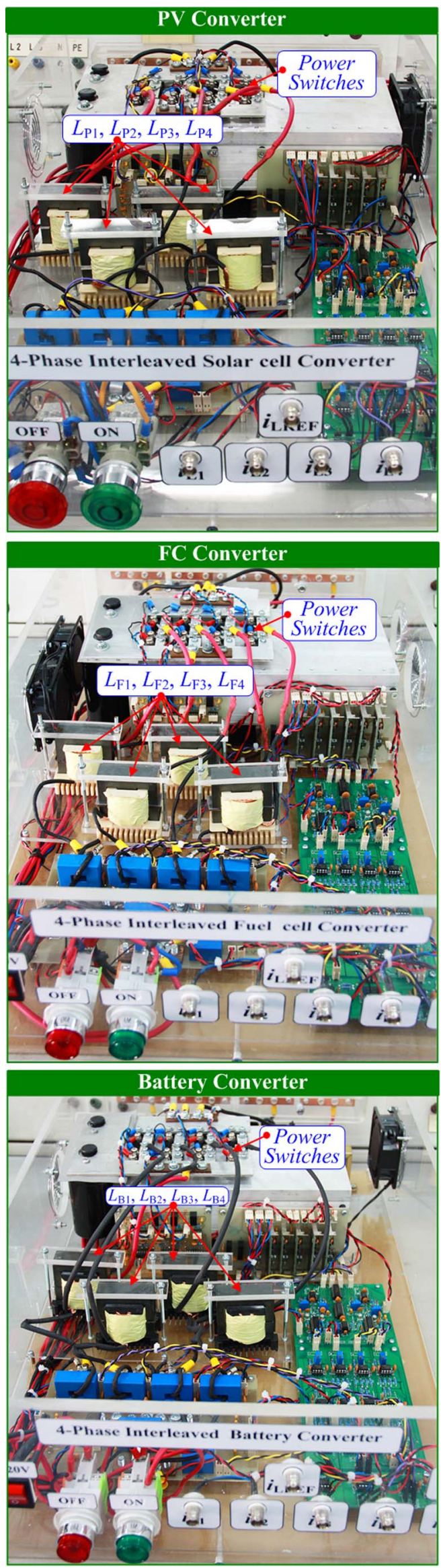

Fig. 10. Photograph of the implemented power converters.
TABLE II

Specifications of the Li-Ion Battery AND the Power Sources

\begin{tabular}{|c|c|c|}
\hline \multicolumn{3}{|c|}{ Fuel Cell System (by Ballard Power Systems Inc): } \\
\hline Rated Power & 1,200 & W \\
\hline Rated Current & 46 & A \\
\hline Rated Voltage & 26 & $\mathrm{~V}$ \\
\hline \multicolumn{3}{|c|}{ Photovoltaic Array (by Ekarat Solar Company): } \\
\hline Number of Panels in Parallel & 4 & \\
\hline Panel Open Circuit Voltage & 33.5 & $\mathrm{~V}$ \\
\hline Panel Rated Voltage & 26 & V \\
\hline Panel Rated Current & 7.7 & A \\
\hline Panel Rated Power & 200 & W \\
\hline Array Rated Power & 800 & W \\
\hline \multicolumn{3}{|c|}{ Li-Ion Battery Bank (by SAFT Technologies Company) } \\
\hline Number of Cells in Series & 6 & \\
\hline Number of String in Parallel & 2 & \\
\hline Cell Maximum Voltage & 4.2 & $\mathrm{~V}$ \\
\hline Bank Capacity $\left(C_{\mathrm{Bat}}\right)$ & 11.6 & $\mathrm{Ah}$ \\
\hline Bank Maximum Voltage & 24 & $\mathrm{~V}$ \\
\hline
\end{tabular}

dSPACE DS1104 (as presented in Fig. 9) through the mathematical environment of MATLAB-Simulink.

\section{REFERENCES}

[1] M. O. Badawy, A. S. Yilmaz, Y. Sozer, and I. Husain, "Parallel power processing topology for solar PV applications," IEEE Trans. Ind. Appl., vol. 50, no. 2, pp. 1245-1255, Mar./Apr. 2014.

[2] U. R. Prasanna, A. K. Rathore, and S. K. Mazumder, "Novel zero-currentswitching current-fed half-bridge isolated dc/dc converter for fuel-cellbased applications," IEEE Trans. Ind. Appl., vol. 49, no. 4, pp. 1658-1668, Jul./Aug. 2013.

[3] P. Thounthong, A. Luksanasakul, P. Koseeyaporn, and B. Davat, "Intelligent model-based control of a standalone photovoltaic/fuel cell power plant with supercapacitor energy storage," IEEE Trans. Sustain. Energy, vol. 4, no. 1, pp. 240-249, Jan. 2013.

[4] M. Amirabadi, H. A. Toliyat, and W. C. Alexander, "A multiport ac link PV inverter with reduced size and weight for stand-alone application," IEEE Trans. Ind. Appl., vol. 49, no. 5, pp. 2217-2228, Sep./Oct. 2013.

[5] J. Kim and B. H. Cho, "Pattern recognition for temperature-dependent state-of-charge/capacity estimation of a Li-ion cell," IEEE Trans. Energy Convers., vol. 28, no. 1, pp. 1-11, Mar. 2013.

[6] M. Petzl and M. A. Danzer, "Advancements in OCV measurement and analysis for lithium-ion batteries," IEEE Trans. Energy Convers., vol. 28 , no. 3, pp. 675-681, Sep. 2013.

[7] V. Samavatian and A. Radan, "A novel low-ripple interleaved buck-boost converter with high efficiency and low oscillation for fuel-cell applications," Int. J. Electr. Power Energy Syst., vol. 63, pp. 446-454, Dec. 2014.

[8] P. Thounthong, P. Tricoli, and B. Davat, "Performance investigation of linear and nonlinear controls for a fuel cell/supercapacitor hybrid power plant," Int. J. Electr. Power Energy Syst., vol. 54, pp. 454-464, Jan. 2014.

[9] P. C. Sekhar and S. Mishra, "Sliding mode based feedback linearizing controller for grid connected multiple fuel cells scenario," Int. J. Electr Power Energy Syst., vol. 60, pp. 190-202, Sep. 2014.

[10] P. Thounthong, S. Raël, and B. Davat, "Control strategy of fuel cell and supercapacitors association for distributed generation system," IEEE Trans. Ind. Electron., vol. 54, no. 6, pp. 3225-3233, Dec. 2007.

[11] M. Fliess, J. Levine, P. h. Martin, and P. Rouchon, "A Lie-Bäcklund approach to equivalence and flatness of nonlinear systems," IEEE Trans. Automat. Contr., vol. 44, no. 5, pp. 922-937, May 1999.

[12] P. Thounthong et al., "Energy management of fuel cell/solar cell/supercapacitor hybrid power source," J. Power Sources, vol. 196, no. 1, pp. 313-324, Jan. 2011.

[13] A. Gensior, T. M. P. Nguyen, J. Rudolph, and H. Güldner, "Flatness-based loss optimization and control of a doubly fed induction generator system," IEEE Trans. Control Syst. Technol., vol. 19, no. 6, pp. 1457-1466, Nov. 2011.

[14] G. Rigatos, P. Siano, and N. Zervos, "Sensorless control of distributed power generators with the derivative-free nonlinear Kalman filter," IEEE Trans. Ind. Electron., vol. 61, no. 11, pp. 6369-6382, Nov. 2014. 
[15] J. Linares-Flores, A. Hernandez Mendez, C. Garcia-Rodriguez, and H. Sira-Ramirez, "Robust nonlinear adaptive control of a "boost" converter via algebraic parameter identification," IEEE Trans. Ind. Electron., vol. 61, no. 8, pp. 4105-4114, Aug. 2014.

[16] E. Song, A. F. Lynch, and V. Dinavahi, "Experimental validation of nonlinear control for a voltage source converter," IEEE Trans. Control Syst. Technol., vol. 17, no. 5, pp. 1135-1144, Sep. 2009.

[17] P. Thounthong, "Model based-energy control of a solar power plant with a supercapacitor for grid-independent applications," IEEE Trans. Energy Convers., vol. 26, no. 4, pp. 1210-1218, Dec. 2011.

[18] A. Battiston et al., "A control strategy for electric traction systems using a PM-motor fed by a bidirectional z-source inverter," IEEE Trans. Veh. Technol., vol. 63, no. 9, pp. 4178-4191, Nov. 2014.

[19] S. Preitl and R. E. Precup, "An extension of tuning relations after symmetrical optimum method for PI and PID controllers," Automatica, vol. 35, no. 10, pp. 1731-1736, Oct. 1999.

[20] K. G. Papadopoulos and N. I. Margaris, "Extending the symmetrical optimum criterion to the design of PID type-p control loops," J. Process Control, vol. 22, no. 1, pp. 11-15, Jan. 2012.

[21] H. Xin, Y. Liu, Z. Qu, and D. Gan, "Distributed control and generation estimation method for integrating high-density photovoltaic systems," IEEE Trans. Energy Convers., vol. 29, no. 4, pp. 988-996, Dec. 2014.

[22] W. Dan, T. Fen, T. Dragicevic, J. C. Vasquez, and J. M. Guerrero, "Autonomous active power control for islanded ac microgrids with photovoltaic generation and energy storage system," IEEE Trans. Energy Convers., vol. 29, no. 4, pp. 882-892, Dec. 2014.

[23] S. K. Kollimalla and M. K. Mishra, "Variable perturbation size adaptive $\mathrm{P} \& \mathrm{O}$ MPPT algorithm for sudden changes in irradiance," IEEE Trans. Sustain. Energy, vol. 5, no. 3, pp. 718-728, Jul. 2014.

[24] S. Moballegh and J. Jin, "Modeling, prediction, experimental validations of power peaks of PV arrays under partial shading conditions," IEEE Trans. Sustain. Energy, vol. 5, no. 1, pp. 293-300, Jan. 2014.

[25] M. Kim et al., "Effects of anode flooding on the performance degradation of polymer electrolyte membrane fuel cells," J. Power Sources, vol. 266, pp. 332-340, Nov. 2014.

[26] Y. Zhan, Y. Guo, J. Zhu, and L. Li, "Current short circuit implementation for performance improvement and lifetime extension of proton exchange membrane fuel cell," J. Power Sources, vol. 270, pp. 183-192, Dec. 2014.

[27] N. Bizon, "Load-following mode control of a standalone renewable/fuel cell hybrid power source," Energy Conv. Manage., vol. 77, pp. 763-772, Jan. 2014

[28] Z. Dongdong, G. Fei, D. Bouquain, D. Manfeng, and A. Miraoui, "Sliding-mode control of an ultrahigh-speed centrifugal compressor for the air management of fuel-cell systems for automotive applications," IEEE Trans. Veh. Technol., vol. 63, no. 1, pp. 51-61, Jan. 2014.

[29] H. El Fadil, F. Giri, J. M. Guerrero, and A. Tahri, "Modeling and nonlinear control of a fuel cell/supercapacitor hybrid energy storage system for electric vehicles," IEEE Trans. Veh. Technol., vol. 63, no. 7, pp. 30113018, Sep. 2014.

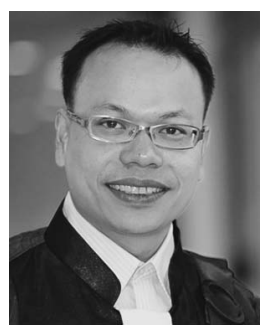

Phatiphat Thounthong (M'09-SM'13) received the B.S. and M.E. degrees in electrical engineering from King Mongkut's Institute of Technology North Bangkok, Bangkok, Thailand, in 1996 and 2001, respectively, and the Ph.D. degree in electrical engineering from the Institut National Polytechnique de Lorraine (INPL), Université de Lorraine, Nancy, France, in 2005.

$\mathrm{He}$ is currently an Associate Professor with the Department of Teacher Training in Electrical Engineering, King Mongkut's University of Technology North Bangkok, Bangkok. His current research interests include power electronics, electric drives, and electrical devices (fuel cells, photovoltaic, wind turbine, batteries, and supercapacitors).

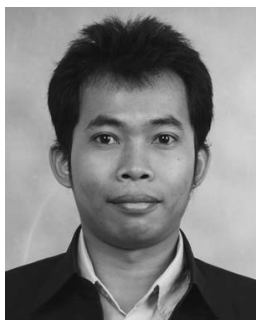

Suwat Sikkabut (M'13) received the B.S. degree in electrical engineering from King Mongkut's Institute of Technology North Bangkok, Bangkok, Thailand, in 2008. He is currently working toward the M.S. degree in electrical engineering at King Mongkut's University of Technology North Bangkok, Bangkok.

His current research interests include power electronics and electrical devices (fuel cells, solar cells, batteries, and supercapacitors).

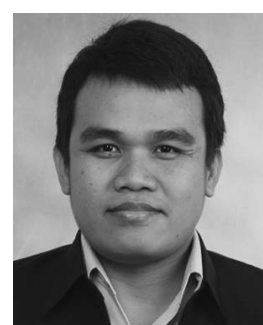

Pongsiri Mungporn received the B.S. degree in electrical engineering from King Mongkut's Institute of Technology North Bangkok, Bangkok, Thailand, in 2008 . He is currently working toward the M.E. degree in electrical engineering at King Mongkut's University of Technology North Bangkok, Bangkok.

His current research interests include power electronics and electrical devices (fuel cells, solar cells, batteries, and supercapacitors).

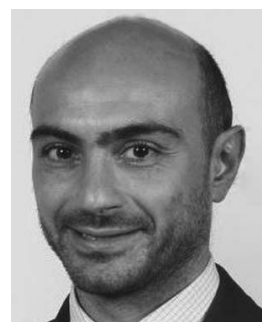

Luigi Piegari (M'04-SM'13) was born in 1975. He received the M.S. and Ph.D. degrees in electrical engineering from the University of Naples Federico II, Naples, Italy, in 1999 and 2003, respectively.

$\mathrm{He}$ is currently an Associate Professor with the Dipartimento di Elettronica, Informazione e Bioingegneria (DEIB), Politecnico di Milano, Milan, Italy. His current research interests include electrical machines, high-efficiency power electronic converters, renewable-energy sources, and storage system modeling.

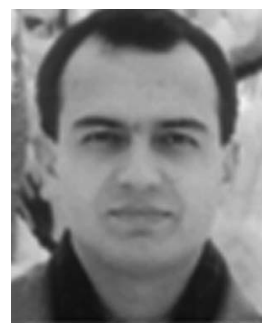

Babak Nahid-Mobarakeh (M'05-SM'12) received the Ph.D. degree in electrical engineering from the Institut National Polytechnique de Lorraine, Nancy, France, in 2001

From 2001 to 2006, he was an Assistant Professor with the Centre de Robotique, Electrotechnique et Automatique, University of Picardie, Amiens, France. In September 2006, he joined the Ecole Superieure d'Electricite et de Mecanique, Université de Lorraine, Nancy, where he is currently an Associate Professor. He is also with the Groupe de Recherche en Electrotechnique et Electronique de Nancy, Nancy. His main research interests include nonlinear and robust control techniques applied to electric systems, fault detection and fault-tolerant control of power systems, and stabilization of microgrids.

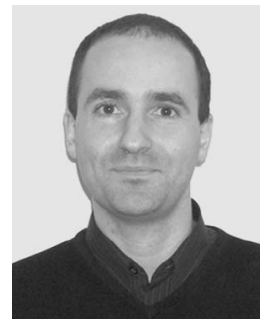

Serge Pierfederici received the Engineer degree from the École Nationale Supérieure en Électricité et Mécanique (ENSEM), Nancy, France, in 1994 and the Ph.D. degree in electrical engineering and the Habilitation à Diriger des Recherches degree (HDR) from the Institut National Polytechnique de Lorraine (INPL), Nancy, in 1998 and 2007, respectively.

Since 2009, he has been a Professor with the Université de Lorraine, Nancy. His research interests include stability study of distributed power systems and modeling and control of power electronic

converters.

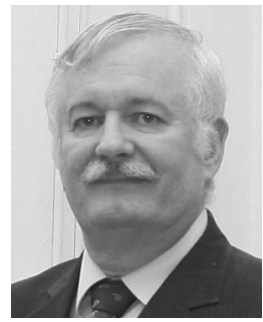

Bernard Davat (M'89) received the Engineer degree from the Ecole Nationale Supérieure d'Electrotechnique, d'Electronique, d' Informatique, d'Hydraulique et des Telecommunications (ENSEEIHT), Toulouse, France, in 1975 and the Ph.D. and Docteur d'Etat degrees in electrical engineering from the Institut National Polytechnique de Toulouse (INPT), Toulouse, in 1978 and 1984, respectively.

From 1980 to 1988 , he was a Researcher with the French National Center for Scientific Research, Laboratoire d'Electrotechnique et d'Electronique Industrielle. Since 1988, he has been a Professor with the Université de Lorraine, Nancy, France, and is currently the Director of the Group of Research in Electrical Engineering of Nancy (GREEN). His research interests include power electronics, drives, and new electrical devices (fuel cells and supercapacitors). 